\title{
Investigating the Growth Behavior of LDH Layers on MAO- coated Aluminum Alloy: Influence of Microstructure and Surface Element
}

\author{
You Zhang ${ }^{1, *}$, Peihang $\mathrm{Yu}^{1,2}$, You Zuo ${ }^{1,2}$, Haoyue Tian ${ }^{1}$, Xiaoyi Chen ${ }^{1}$ and Fei Chen ${ }^{1, *}$ \\ ${ }^{1}$ College of Materials Science and Engineering, Beijing Institute of Petrochemical Technology, \\ Beijing 102617, China \\ ${ }^{2}$ College of Materials Science and Engineering, Beijing University of Chemical Technology, Beijing \\ 100029, China \\ *E-mail: youzhang@bipt.edu.cn, chenfei@bipt.edu.cn
}

doi: $10.20964 / 2018.01 .53$

Received: 5 October 2017 / Accepted: 10 November 2017 / Published: 16 December 2017

Layered double hydroxide (LDH) layers were grown in-situ on the surface of micro-arc oxidation (MAO) ceramic coating applied on 2024 aluminum alloy. It was found that the microstructure and surface element of MAO film have a significant effect on the growth behavior of LDH layers. In the initial stage of growth, LDHs grains can be preferentially formed in/on the micro-pores/-cracks of MAO coating to provide effective film repairs. However, some surface regions on MAO coating were not still covered by the LDH layers after long time of growth. The results showed that the content of $\mathrm{Si}$ element was higher in the regions without LDH nanoplatelets growth. Therefore, we use two approaches to investigate influence of surface $\mathrm{Si}$ element on the growth behavior of LDH layers on MAO coating: one is to replace the $\mathrm{Na}_{2} \mathrm{SiO}_{4}$ electrolyte to $\mathrm{NaAlO}_{2}$ electrolyte used in the MAO process, removing the content of $\mathrm{Si}$ on the surface of MAO coating; another is to polish the MAO coating, reducing the enriched Si elements of the outer layer. After removing of surface Si, the LDH layers were uniformly and completely covered on the surface of MAO coating during the growth process. The results demonstrate that the distribution of Si element on the MAO surface significantly inhibit the nucleation and growth of LDH grains.

Keywords: Layered double hydroxide; Micro-arc oxidation; Film; Growth behavior; Aluminum alloy

\section{FULL TEXT}

(C) 2018 The Authors. Published by ESG (www.electrochemsci.org). This article is an open access article distributed under the terms and conditions of the Creative Commons Attribution license (http://creativecommons.org/licenses/by/4.0/). 